\title{
Primary Care Physician Stress Driven by Social and Financial Needs of Complex Patients
}

\author{
Jonathan Z. Weiner, MD, MPH, Jodi K. McCloskey, MPH, Connie S. Uratsu, MSN, PHN, and \\ Richard W. Grant, MD, MPH
}

Division of Research, Kaiser Permanente Northern California, Oakland, CA, USA.

J Gen Intern Med 34(6):818-9

DOI: $10.1007 / \mathrm{s} 11606-018-4815-\mathrm{x}$

(๑) Society of General Internal Medicine 2019

\section{INTRODUCTION}

Caring for complex patients may be an underreported source of stress for primary care physicians (PCPs). Prior research on reducing physician burnout has largely focused on communication, work-life balance, and self-management techniques. ${ }^{1}$ Perceived patient complexity has been linked to decreased PCP work satisfaction, but little is known about how specific components of patient complexity such as socioeconomic or personal circumstances, burden of medical conditions, or behavioral health impact PCP stress. ${ }^{2,3}$ We examined the association between PCP self-reported stress and the factors that define their most complex patients.

\section{METHODS}

PCPs from a large integrated health care system in Northern California completed a survey as part of a quality improvement project related to complex patient care management. Printed surveys were distributed to 156 PCPs from 6 community primary care practices across 3 medical facilities with similar access to case management services. The survey prompted PCPs to consider their 10-15 most complex, challenging patients and asked them to report levels of stress and ease of care coordination. PCPs were also asked to rate the importance of pre-defined patient factors that contribute to making complex patients challenging to manage (Table 1). For our analysis, we dichotomized responses as very high or high importance vs. moderate or low importance and compared PCPs reporting "extreme" stress vs. lower stress levels (moderate, somewhat, or low). We used multivariate logistic regression to control for years' experience with their employer to adjust for familiarity with practice setting. This study was reviewed by the Research Determination Office of Kaiser Permanente of Northern California and deemed to be quality

Prior Presentations Scientific Oral Abstract Presentation, 2018 Society for General Internal Medicine Annual Conference, April 11th-14th, Denver, $\mathrm{CO}$

Published online January 8, 2019 improvement exempt from full review by a KP Institutional Review Board.

RESULTS

The survey response rate was $87 \%$ (135/156). PCP respondents were $65 \%$ women; $77 \%$ were internal medicine and $23 \%$ were family medicine trained. The mean years from medical school graduation was 20.9 (SD 8.2) years. Over half $(56 \%)$ of physicians had $>10$ years' experience in their current practice setting. Social or financial issues, poor patient adherence, and pain management were among the most commonly cited patient complexity factors (Table 1 ).

Overall, $80 \%$ of PCPs reported their work with complex patients to be either moderately stressful (47\%) or extremely stressful (32\%). In multivariate analyses, PCPs who reported extreme stress were significantly more likely to rate social or financial issues (aOR 4.43; 1.24-15.28) as the most relevant contributors to defining their complex patients but not other patient factors like number of diagnoses or pain management (Table 1). PCPs reporting extreme stress were also more likely to report greater difficulty with care coordination $(2.20 ; 1.01-$ 4.79).

\section{DISCUSSION}

Most PCPs reported that primary care of complex patients was moderately or extremely stressful, and PCPs reporting the greatest stress were more likely to identify the contribution of patients' social or financial issues rather than medical or behavioral problems as major management challenges.

Even though social adversity and poor health are linked, programs that meet patients' social and financial needs are uncommon. ${ }^{4}$ Without such resources, PCPs can become de facto responsible for these issues. PCPs have the training, experience, and resources to treat patients' medical needs, but management of socioeconomic difficulties may lie outside of physicians' expertise or workflow. ${ }^{5}$ Without the necessary resources, physicians can feel ill-equipped to provide the interventions patients truly need, contributing to increased stress.

We used cross-sectional self-report survey data, so our results must be interpreted in the context of the study design. 
Table 1 PCP Rating of Factors That Contribute to the Challenge of Managing Complex Patients, by Self-reported Physician Stress Level

\begin{tabular}{|c|c|c|c|}
\hline $\begin{array}{l}\text { Factors that } \\
\text { contribute to } \\
\text { patient } \\
\text { complexity }\end{array}$ & $\begin{array}{l}\text { PCPs } \\
\text { reporting } \\
\text { extreme stress } \\
(n=43)\end{array}$ & $\begin{array}{l}\text { PCPs } \\
\text { reporting } \\
\text { lower stress } \\
(n=92)\end{array}$ & $\begin{array}{l}\text { aOR } \\
(95 \% \mathrm{CI})\end{array}$ \\
\hline \multicolumn{4}{|c|}{ Socioeconomic or personal circumstances, $\%$ rated very high/high } \\
\hline $\begin{array}{l}\text { Social or } \\
\text { financial issues }\end{array}$ & 93.0 & 75.6 & $\begin{array}{l}4.43 \\
(1.24 \\
15.28) *\end{array}$ \\
\hline $\begin{array}{l}\text { Poor patient } \\
\text { adherence and } \\
\text { self-management }\end{array}$ & 88.4 & 77.8 & $\begin{array}{l}2.83 \\
(0.90- \\
8.90)\end{array}$ \\
\hline Frail elderly & 81.4 & 66.7 & $\begin{array}{l}2.14 \\
(0.88 \\
5.25)\end{array}$ \\
\hline $\begin{array}{l}\text { Excessive use of } \\
\text { care services }\end{array}$ & 70.0 & 60.0 & $\begin{array}{l}1.76 \\
(0.80- \\
3.90)\end{array}$ \\
\hline $\begin{array}{l}\text { Language barriers } \\
\text { or cultural beliefs }\end{array}$ & 50.0 & 34.4 & $\begin{array}{l}1.99 \\
(0.93- \\
4.24)\end{array}$ \\
\hline \multicolumn{4}{|c|}{ Medical or behavioral Issues, $\%$} \\
\hline Pain management & 85.7 & 72.2 & $\begin{array}{l}2.34 \\
(0.87- \\
6.46)\end{array}$ \\
\hline $\begin{array}{l}\text { Mental health } \\
\text { problems }\end{array}$ & 81.0 & 73.3 & $\begin{array}{l}1.46 \\
(0.59- \\
3.62)\end{array}$ \\
\hline $\begin{array}{l}\text { \# of prescribed } \\
\text { medicines }\end{array}$ & 60.5 & 70.0 & $\begin{array}{l}0.66 \\
(0.30- \\
1.44)\end{array}$ \\
\hline $\begin{array}{l}\text { \# of medical } \\
\text { diagnoses }\end{array}$ & 65.1 & 60.0 & $\begin{array}{l}1.20 \\
(0.56- \\
2.58)\end{array}$ \\
\hline End-of-life issues & 53.7 & 56.2 & $\begin{array}{l}0.98 \\
(0.46- \\
2.08)\end{array}$ \\
\hline Substance use & 50.0 & 53.4 & $\begin{array}{l}0.80 \\
(0.38- \\
1.69)\end{array}$ \\
\hline
\end{tabular}

PCP self-reported stress dichotomized as "Extreme" vs. "Moderatel Somewhat/Low." Column percentages are the proportion of PCPS who responded either "very high" or "high" to the extent that each listed factor contributed to making their complex patients challenging to manage. aOR: Odds ratios are adjusted for years' experience with employer to adjust for familiarity with practice setting

*Statistically significant

While we were unable to use objective measures of patient complexity, PCP-defined patient complexity is well established in the literature. ${ }^{3}$ We found that several nonmedical patient factors had an association with extreme stress but did not reach statistical significance due to wide confidence intervals. Despite a robust response rate, this was likely due to sample size constraints. Nevertheless, this correlation supports the notion that PCP stress is not driven by medical complexity alone and could be further investigated in a larger study.

Our results suggest that the existing systems of care delivery for socially complex patients contribute to extreme PCP stress and that improving care coordination may be protective. Efforts to reduce PCP burnout should therefore recognize the impact of caring for complex patients with limited social and financial resources on PCP stress by implementing interventions to address patients' unmet needs.

Corresponding Author: Jonathan Z. Weiner, MD, MPH; Division of Research, Kaiser Permanente Northern California, 2000 Broadway, Oakland, CA 94612, USA (e-mail: jonathan.z.weiner@kp.org).

Contributors There were no additional contributors to this manuscript beyond the listed authors.

Funders External grant funding was provided by the National Institute of Diabetes and Digestive and Kidney Diseases under project number 5K24DK109114-02. Internal funding awarded by Kaiser Permanente of Northern California (No grant number associated). JZW was supported by the Division of Research Delivery Science Fellowship Program.

\section{Compliance with Ethical Standards:}

This study was reviewed by the Research Determination Office of Kaiser Permanente of Northern California and deemed to be quality improvement exempt from full review by a KP Institutional Review Board.

Conflict of Interest: The authors declare that they do not have a conflict of interest.

Prior Presentations: Scientific Oral Abstract Presentation, 2018 Society for General Internal Medicine Annual Conference, April 11th14th, Denver, CO

\section{REFERENCES}

1. Panagioti, M., Panagopoulou E., Bower P., et al. Controlled Interventions to Reduce Burnout in Physicians: A Systematic Review and Meta-analysis. JAMA Intern Med. 2017;177(2): 195-205.

2. Katerndahl, D., Parchman, M., and Wood, R. Perceived complexity of care, perceived autonomy, and career satisfaction among primary care physicians. J Am Board Fam Med. 2009;22(1): 24-33.

3. Grant, R.W., Ashburner, J., Hong, C.S., Chang, Y., Barry, M.J., Atlas, S.J. 2011. Defining Patient Complexity From the Primary Care Physician's Perspective: A Cohort Study. Ann Internal Med. 2011;155(12): 797-84.

4. Gottlieb, L. M., et al. A Systematic Review of Interventions on Patients Social and Economic Needs. Am J Prev Med. 2017; 53(5): 719-729.

5. Hong, C.S., Atlas, S.J., Chang, Y., et al. Relationship Between Patient Panel Characteristics and Primary Care Physician Clinical Performance Rankings. JAMA. 2010;304(10):1107-13. 